\title{
Acute Massive Pulmonary Embolism with Direct Visualization of a Free-floating Right Heart Thrombus Successfully Treated with Fibrinolysis: A Case Report
}

\author{
Elisavet Kaitalidou', Dimitrios Karapiperis ${ }^{2}$, Vasileios Makrakis ${ }^{3}$, \\ Maria Kipourou4, Dimitrios Petroglou ${ }^{5}$ \\ ${ }^{1}$ Department of Internal Medicine, 424 General Military Hospital, Thessaloniki, \\ Greece; \\ ${ }^{2}$ Department of Infectious Diseases, 424 General Military Hospital, Thessaloniki, \\ Greece; \\ ${ }^{3}$ Intensive Care Unit, 424 General Military Hospital, Thessaloniki, Greece; \\ ${ }^{4}$ Department of Pulmonology, 424 General Military Hospital, Thessaloniki, Greece; \\ ${ }^{5}$ Coronary Care Unit, Department of Cardiology, 424 General Military Hospital, \\ Thessaloniki, Greece
}

Received February 7, 2019; Accepted February 17, 2020.

Key words: Pulmonary embolism - Right heart thrombus - Fibrinolysis - Bedside echocardiography

\begin{abstract}
A male patient with a history of immobilization due to motor weakness, was transferred to our emergency department after syncope during physiotherapy, with recorded hypotension. Transthoracic echocardiography showed severe dilatation of the right ventricle (RV), with apex hypercontractility and almost akinetic RV free wall. The above findings, in addition to the unexpected visualization of a large, free-floating, right atrial thrombus, a rare finding associated with high mortality, readily confirmed the clinical suspicion of acute pulmonary embolism (PE) causing circulatory collapse. Intravenous fibrinolysis and vasopressor therapy were successfully administered, and hemodynamic instability was soon alleviated.
\end{abstract}

Mailing Address: Dimitrios Petroglou, MD., PhD., Coronary Care Unit, Department of Cardiology, 424 General Military Hospital, Thessaloniki Ring Road, N. Efkarpia, Thessaloniki 56429, Greece; Phones: (+30) 23103812 93, (+30) 69722220 87; e-mail: dimpetroglou@yahoo.gr 


\section{Introduction}

Venous thromboembolism is a major health problem with acute pulmonary embolism (PE) being its most serious clinical presentation (Cohen et al., 2007). PE occurs when a portion of a clot from a deep vein thrombosis breaks off, travels through the right heart, and eventually lodges in the pulmonary vasculature (Giordano et al., 2017). To this day, epidemiology of PE is difficult to determine, and its incidence is estimated around 100 to 200 cases per 100,000 people (Huang et al., 2014; Martinez et al., 2014). Well known risk factors that increase likelihood of developing PE include surgery, trauma, prolonged immobility, cancer and estrogen use (Giordano et al., 2017). Prompt diagnosis may be difficult, since its clinical signs and symptoms (dyspnea, pleuritic chest pain, cough) are non-specific. Arterial hypotension and shock are rare but important clinical presentations, indicating massive PE or severely reduced hemodynamic reserve. Given the fact that PE is a major cause of morbidity, mortality and hospitalization, when clinical presentation raises the suspicion of $\mathrm{PE}$, further objective testing should be prompted (Konstantinides et al., 2014).

\section{Case report}

A 63-year-old male was transferred to our emergency department after syncope during physiotherapy, with recorded hypotension. He had a history of essential arterial hypertension [amlodipine $10 \mathrm{mg}$ once daily (od), valsartan $160 \mathrm{mg}$ od, nebivolol $2.5 \mathrm{mg}$ od], dyslipidemia (simvastatin $10 \mathrm{mg}$ od, ezetimibe $10 \mathrm{mg}$ od), symptomatic hyperuricemia (allopurinol $100 \mathrm{mg}$ od), depression (sertraline $50 \mathrm{mg}$ od, lorazepam $1.25 \mathrm{mg}$ od) and benign prostate hyperplasia (solifenacin $6 \mathrm{mg}$ od, tamsulosin $0.4 \mathrm{mg}$ od). He had also been diagnosed with Parkinsonism [levodopa $50 \mathrm{mg}$ twice daily (bid), benserazide $12.5 \mathrm{mg}$ bid, pramipexole $2.1 \mathrm{mg}$ od] and syringohydromyelia with severe motor weakness, due to which he remained bedridden. The patient had been recently hospitalized because of progressive motor weakness and hyponatremia and was discharged on prophylactic anticoagulation therapy [3,500 international units (IU) of tinzaparin od] and physiotherapy recommendation.

Initial clinical examination revealed blood pressure of $70 / 50$ millimetres of mercury $(\mathrm{mm} \mathrm{Hg})$, heart rate of 125 beats per minute, temperature of $36.6^{\circ} \mathrm{C}$ and oxygen saturation of $97 \%$ on room air. His electrocardiogram showed sinus tachycardia with right bundle branch block pattern. Laboratory investigations were as follows: hemoglobin: $11.8 \mathrm{~g} / \mathrm{dl}$, total leucocyte count: 18,760 per $\mu$ l with $82.5 \%$ neutrophils, serum urea: $67.46 \mathrm{mg} / \mathrm{dl}$, AST: $85 \mathrm{U} / \mathrm{I}$, ALT: $93.2 \mathrm{U} / \mathrm{I}, \mathrm{LDH}: 387.5 \mathrm{U} / \mathrm{l}$, CRP: $1.01 \mathrm{mg} / \mathrm{dl}$, potassium: $2.79 \mathrm{mmol} / \mathrm{l}$, D-dimers of $2.23 \mathrm{mg} / \mathrm{dl}$ (upper normal limit: $0.05 \mathrm{mg} / \mathrm{dl}$ ) and a negative troponin test.

Patient was conscious and hypotension was initially treated with fluid resuscitation, unsuccessfully. Because of recent history of immobilization, in conjunction with persistent hemodynamic instability and D-dimers count rise, acute 


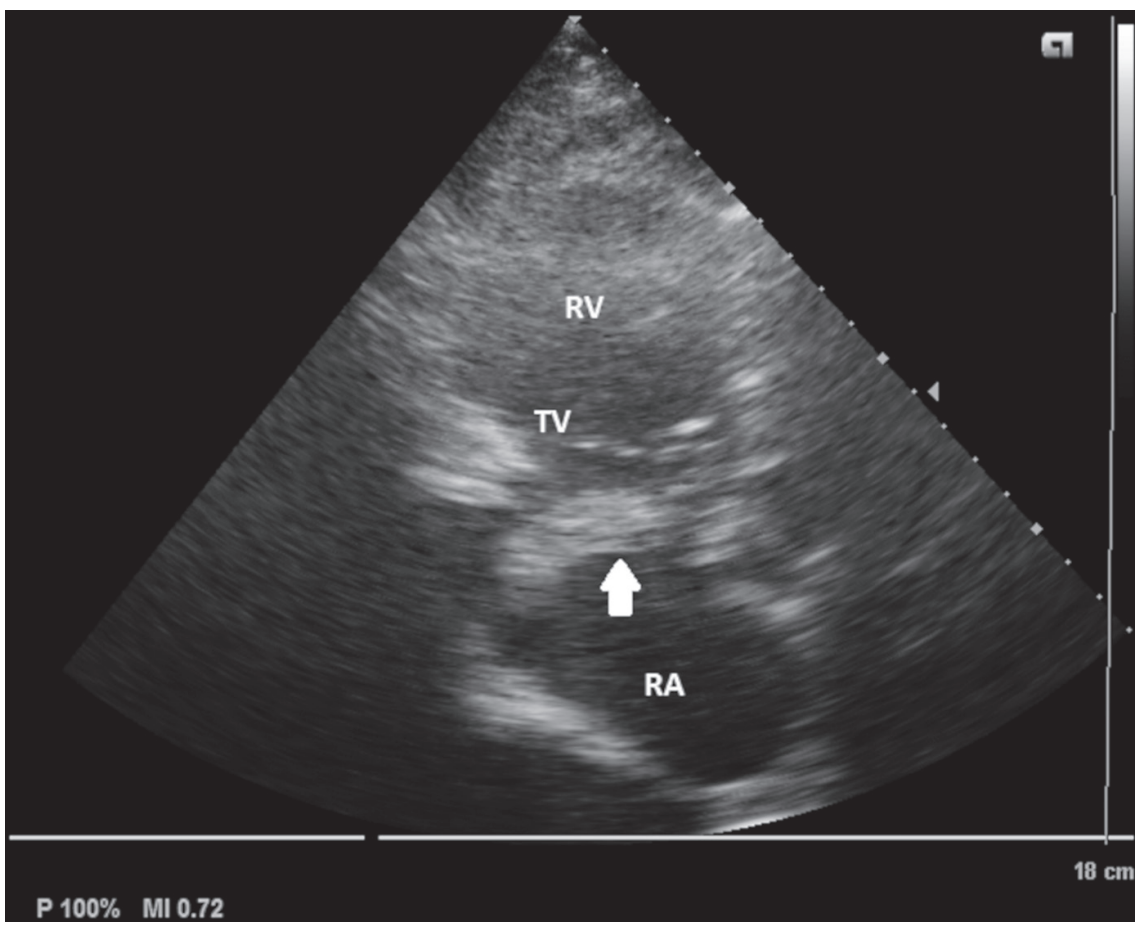

Figure 1 - Bedside echocardiography revealed a large, elongated, free-floating thrombus (white arrow) in the right atrium (RA - right atrium; TV - tricuspid valve; $R V$ - right ventricle).

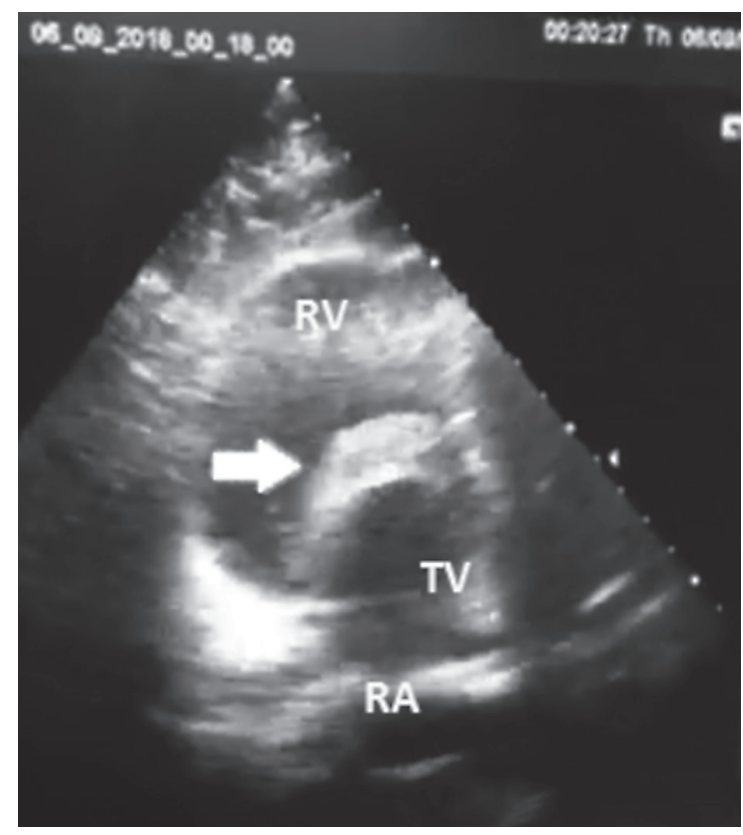

Figure 2 - Right atrial thrombus (white arrow) protruding through the tricuspid valve into the right ventricle, during end diastole (RA - right atrium; TV - tricuspid valve; $R V$ - right ventricle).

Kaitalidou E.; Karapiperis D.; Makrakis V.; Kipourou M.; Petroglou D. 
PE was suspected, and bedside transthoracic echocardiography was performed. The RV (right ventricle) was severely dilated (right/left basal ventricular diameter ratio: 1.2), with apex hypercontractility, while RV free wall was almost akinetic (McConnell's sign). RV systolic pressure (RVSP) using tricuspid regurgitation flow was calculated $58 \mathrm{~mm} \mathrm{Hg}$. Findings above were highly indicative of massive PE. Unexpectedly, direct visualization of a large, elongated, free-floating, right atrial thrombus (Figure 1), originating from the inferior vena cava and protruding through the tricuspid valve during end-diastole (Figure 2), readily confirmed the diagnosis.

No further imaging was deemed necessary. Five thousand IU of unfractionated heparin were infused intravenously, and the patient was admitted to the coronary care unit (CCU). Since cardiothoracic surgery department is not available on site, and due to the patient's hemodynamic instability, fibrinolysis with $100 \mathrm{mg}$ of intravenous recombinant tissue plasminogen activator (rtPA - Alteplase) was initiated, along with norepinephrine, a vasopressor with known beneficial effect on $\mathrm{RV}$ contractility. Fibrinolytic and vasopressor therapy soon alleviated hemodynamic instability, while no right heart thrombus was visible one hour after fibrinolysis completion. Twelve hours later, vasopressor therapy was gradually withdrawn, and the patient started treatment with therapeutic dose of tinzaparin (14,000 IU od).

During his two-day stay in the CCU the patient remained hemodynamically stable. Computed tomography pulmonary angiogram (CTPA) before his discharge

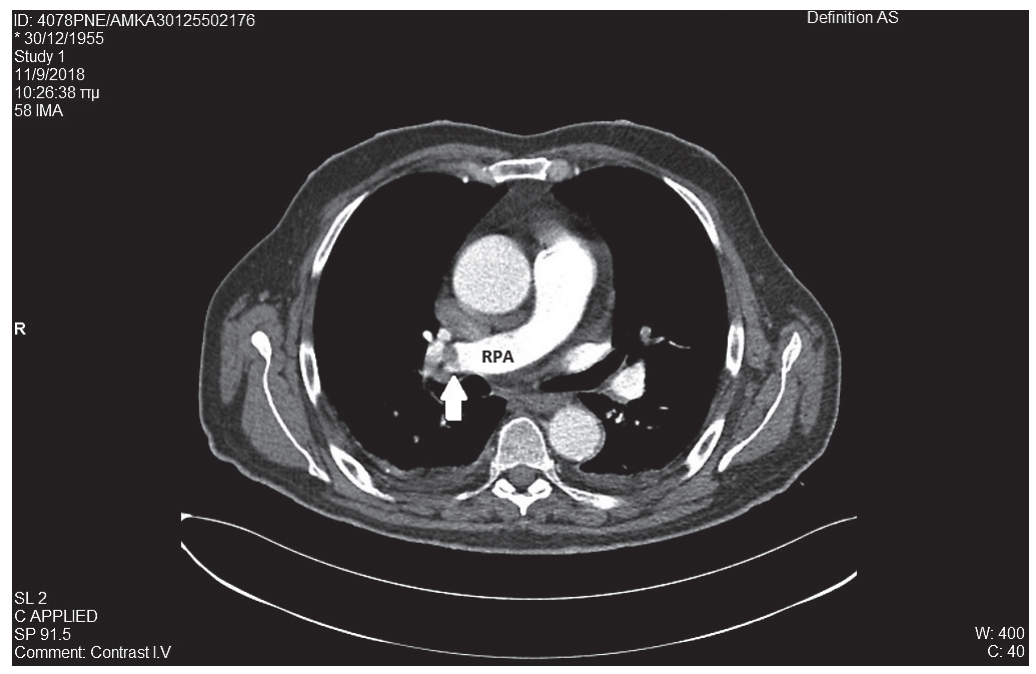

Figure 3 - CTPA after fibrinolysis and hemodynamic stabilization revealed a large, residual thrombus (white arrow) in the main branch of the right pulmonary artery (CTPA - computed tomography pulmonary angiogram; RPA - right pulmonary artery). 
from the CCU to the ward, demonstrated a large thrombus in the main branch of the right pulmonary artery (Figure 3). Follow-up transthoracic echocardiography on the fifth hospital day revealed normal contractility of the RV, its size being marginally normal (right/left basal ventricular diameter ratio: 0.9), RVSP of $35 \mathrm{~mm} \mathrm{Hg}$ and absence of thrombi in right heart chambers. After one week of hospitalization, patient was discharged on warfarin, with an international normalized ratio (INR) target of 2.5 (between two and three).

\section{Discussion}

In this report, we present a case of an acute massive PE with direct echocardiographic visualization of a large, free-floating, right atrial thrombus, protruding through the tricuspid valve during end-diastole. The differential diagnosis in our case, a combination of syncope and hemodynamic instability, included acute coronary syndrome, pulmonary embolism, acute valvular dysfunction, tamponade and aortic dissection. Bedside transthoracic echocardiography is the most useful initial test in this situation and, thus, it was immediately performed. The simultaneous presence of a mobile right heart thrombus (RiHT) with severe RV dysfunction essentially confirmed the diagnosis of PE (Konstantinides et al., 2014). RiHT can be detected by echocardiography in $\sim 4 \%$ of PE patients, its presence being associated with high mortality (Torbicki et al., 2003; Koc et al., 2016). They can easily embolize to the pulmonary arterial tree compromising pulmonary circulation, causing severe hypoxia and sudden cardiac death, thus rendering their immediate treatment mandatory (Chapoutot et al., 1996).

The presence of a mobile RiHT, however, renders optimal treatment significantly different than anticoagulation alone, which is the standard treatment in uncomplicated PE (Torbicki et al., 2003). Recommendations for mobile RiHT treatment include fibrinolytic therapy and surgical pulmonary embolectomy. Current European Society of Cardiology (ESC) guidelines indicate systemic fibrinolysis as the treatment of choice for patients with PE and hemodynamic instability, leaving surgical embolectomy as an alternative in case fibrinolysis is absolutely contraindicated or has failed to improve hemodynamic status (Konstantinides et al., 2014). Furthermore, in 2018, Burgos et al. published a systematic review comparing the treatment strategies for patients with free-floating RiHT, reaching to the conclusion that fibrinolysis and surgical embolectomy show similar results and that the treatment of choice relies on proper individualization of the risks and benefits of both techniques. Of note, although novel anticoagulants (NOACs) are a convenient choice for long term, orally administered anticoagulation in patients with uncomplicated PE, patients who received fibrinolysis were excluded from relevant studies, leaving vitamin $\mathrm{K}$ antagonists (warfarin) as the only evidence-based choice for orally administered therapy in this specific population (Schulman et al., 2009, 2014; Buller et al., 2012; Agnelli et al., 2013). 


\section{Conclusion}

This case demonstrates the value of bedside echocardiography in diagnostic assessment of hemodynamically compromised patients. Furthermore, acute massive PE should be a diagnosis to consider in patients presenting with hemodynamic instability. Finally, echocardiographic visualization of a mobile RiHT is a rather rare finding associated with high mortality. Thus, prompt treatment, either with fibrinolysis or with surgical thrombectomy, can be life-saving.

\section{References}

Agnelli, G., Buller, H. R., Cohen, A., Curto, M., Gallus, A. S., Johnson, M., Masiukiewicz, U., Pak, R., Thompson, J., Raskob, G. E., Weitz, J. I. (2013) Oral apixaban for the treatment of acute venous thromboembolism. N. Engl. J. Med. 369(9), 799-808.

Buller, H. R., Prins, M. H., Lensin, A. W., Decousus, H., Jacobson, B. F., Minar, E., Chlumsky, J., Verhamme, P., Wells, P., Agnelli, G., Cohen, A., Berkowitz, S. D., Bounameaux, H., Davidson, B. L., Misselwitz, F., Gallus, A. S., Raskob, G. E., Schellong, S., Segers, A. (2012) Oral rivaroxaban for the treatment of symptomatic pulmonary embolism. N. Engl. J. Med. 366(14), 1287-1297.

Burgos, L. M., Costabel, J. P., Galizia Brito, V., Sigal, A., Maymo, D., Iribarren, A., Trivi, M. (2018) Floating right heart thrombi: A pooled analysis of cases reported over the past 10 years. Am. J. Emerg. Med. 36(6), 911-915.

Chapoutot, L., Nazeyrollas, P., Metz, D., Maes, D., Maillier, B., Jennesseaux, C., Elaerts, J. (1996) Floating right heart thrombi and pulmonary embolism: Diagnosis, outcome and therapeutic management. Cardiology 87(2), 169-174.

Cohen, A. T., Agnelli, G., Anderson, F. A., Arcelus, J. I., Bergqvist, D., Brecht, J. G., Greer, I. A., Heit, J. A., Hutchinson, J. L., Kakkar, A. K., Mottier, D., Oger, E., Samama, M. M., Spanagl, M. (2007) Venous thromboembolism (VTE) in Europe. The number of VTE events and associated morbidity and mortality. Thromb. Haemost. 98(4), 756-764.

Giordano, N. J., Jansson, P. S., Young, M. N., Hagan, K. A., Kabrhel, K. (2017) Epidemiology, pathophysiology, stratification, and natural history of pulmonary embolism. Tech. Vasc. Interv. Radiol. 20(3), 135-140.

Huang, W., Goldberg, R. J., Anderson, F. A., Kiefe, C. I., Spencer, F. A. (2014) Secular trends in occurrence of acute venous thromboembolism: The Worcester VTE study (1985-2009). Am. J. Med. 127(9), 829-839.

Koc, M., Kostrubiec, M., Elikowski, W., Meneveau, N., Lankeit, M., Grifoni, S., Kuch-Wocial, A., Petris, A., Zaborska, B., Stefanović, B. S., Hugues, T., Torbicki, A., Konstantinides, S., Pruszczyk, P. (2016) Outcome of patients with right heart thrombi: The right heart thrombi European registry. Eur. Respir. J. 47(3), 869-875.

Konstantinides, S. V., Torbicki, A., Agnelli, G., Danchin, N., Fitzmaurice, D., Galiè, N., Gibbs, J. S., Huisman, M. V., Humbert, M., Kucher, N., Lang, I., Lankeit, M., Lekakis, J., Maack, C., Mayer, E., Meneveau, N., Perrier, A., Pruszczyk, P., Rasmussen, L. H., Schindler, T. H., Svitil, P., Vonk Noordegraaf, A., Zamorano, J. L., Zompatori, M. (2014) 2014 ESC guidelines on the diagnosis and management of acute pulmonary embolism: The task force for the diagnosis and management of acute pulmonary embolism of the European Society of Cardiology (ESC). Eur. Heart J. 35(43), 3033-3069.

Martinez, C., Cohen, A. T., Bamber, L., Rietbrock, S. (2014) Epidemiology of first and recurrent venous thromboembolism: A population-based cohort study in patients without active cancer. Thromb. Haemost. 112(2), 255-263. 
Schulman, S., Kearon, C., Kakkar, A. K., Mismetti, P., Schellong, S., Eriksson, H., Baanstra, D., Schnee, J., Goldhaber, S. Z. (2009) Dabigatran versus warfarin in the treatment of acute venous thromboembolism. N. Engl. J. Med. 361(24), 2342-2352.

Schulman, S., Kakkar, A. K., Goldhaber, S. Z., Schellong, S., Eriksson, H., Mismetti, P., Christiansen, A. V., Friedman, J., Le Maulf, F., Peter, N., Kearon, C. (2014) Treatment of acute venous thromboembolism with dabigatran or warfarin and pooled analysis. Circulation 129(7), 764-772.

Torbicki, A., Galie, N., Covezzoli, A., Rossi, E., De Rosa, M., Goldhaber, S. Z. (2003) Right heart thrombi in pulmonary embolism: Results from the international cooperative pulmonary embolism registry. J. Am. Coll. Cardiol. 41(12), 2245-2251. 